\title{
Remote Pre-Diagnosis of Pes Planus and Pes Cavus Using Arch Index
}

\author{
Kaan Eksen ${ }^{1 *}$, Safa Serif ${ }^{2}$, Tacha Serif ${ }^{3}$ \\ ${ }^{1 *}$ Yeditepe University, Faculty of Engineering, Departmant of Computer Engineering, İstanbul, Turkey, (ORCID: 0000-0001-5774-3807), kaan.eksen@persystlab.org \\ 2 General Hospital of Komotini "Sismanoglio", Komotini, Greece, (ORCID: 0000-0001-5458-656X), safa@drserif.com \\ ${ }^{3}$ Yeditepe University, Faculty of Engineering, Departmant of Computer Engineering, İstanbul, Turkey, (ORCID: 0000-0003-1819-4926), tacha.serif@persystlab.org
}

(1st International Conference on Applied Engineering and Natural Sciences ICAENS 2021, November 1-3, 2021)

(DOI: 10.31590/ejosat.1015097)

ATIF/REFERENCE: Eksen, K., Serif, S. \& Serif, T. (2021). Remote Pre-Diagnosis of Pes Planus and Pes Cavus Using Arch Index. European Journal of Science and Technology, (28), 1321-1329.

\begin{abstract}
According to the literature, people with foot deformities report poor quality of life and nearly one-third of the population has some type of foot deformity. Of all the deformities, Pes Planus, caused by the loss of the medial longitudinal arch of the foot, and pes cavus, caused by having an abnormally high plantar longitudinal arch, are the ones that negatively influence the productivity of society most. In the light of the above, this study proposes a novel mobile pre-diagnosis system for pes planus and pes cavus that is utilizing conventional deformity identification methods accepted in the literature through a mobile phone app by harnesing image processing and deep neural networks. As part of the study, a prototype is implemented and tested using 34 participants - 22 (64.71\%) males and 12 (35.29\%) females - with an average age of 24.06. In order to benchmark our prototype, an orthopedic specialist was asked to identify the key decision making points, which was then used to calculate the deformity type, on a set of foot images collected from participants. Then the same images were fed to the prototype with the objective of identifying the key points and calculating the deformity type via the help of image processing and deep learning algorithms. The comparison of the results showed that specialist's and prototypes findings were in $91.80 \%$ match, which indicated an overall success.
\end{abstract}

Keywords: Pes Planus, Pes Cavus, Vision, Image Processing, Orthopedics, Deep Learning

\section{Arch Index ile Pes Planus ve Pes Kavus'un Uzaktan Ön Tanısı}

\section{$\ddot{O} \mathbf{z}$}

Literatüre göre nüfusun yaklaşık üçte birinin bir tür ayak deformitesine sahip olduğu ve bunun kişilerin yaşam kalitesinin düşürdüğü bilinmektedir. Tüm deformiteler içinde ayağın medial longitudinal arkının kaybından kaynaklanan Pes Planus ve anormal derecede yüksek plantar longitudinal arkın neden olduğu pes cavus toplum verimliliğini en çok olumsuz etkileyen deformitelerdendir. Yukarıdakiler ışığında, bu çalışmada pes planus ve pes cavus için literatürde kabul gören geleneksel deformite tanımlama yöntemlerini kullanan, görüntü işleme ve derin sinir ağları yardımıyla bir cep telefonu uygulaması konsepti geliştirilmesiyle birlikte yeni bir mobil ön tanı sistemi sunulmuştur. Çalışma kapsamında, yaş ortalaması 24,06 olan ve bunların 22'si (\%64,71) erkek ve 12'si (\%35,29) kadın olmak üzere toplamda 34 katılımcı üzerinde bir prototip mobil çözüm uygulanmış ve test edilmiştir. Çalışma boyunca, çalışmaya katılan katılımcılardan ayak görüntüleri toplanmış ve bir ortopedi uzmanından deformite tiplerini hesaplamak için kullanılan kilit karar verme noktalarının belirlenmesi istenmiştir. Daha sonra aynı görüntüler, görüntü işleme ve derin öğrenme algoritmaları yardımıyla kilit noktaları belirlemek ve deformite tipini hesaplamak amacıyla prototipe beslenmiştir. Sonuçların karşılaştırılması, uzman ve prototip bulgularının \%91.80 oranında uyum içinde olduğunu göstermiş ve bu da genel bir başarıya işaret etmiştir.

Anahtar Kelimeler: Pes Planus, Pes Cavus, Görüntü İşleme, Ortopedi, Derin Öğrenme.

\footnotetext{
* Corresponding Author: kaan.eksen@persyslab.org
} 


\section{Introduction}

All of the organs and bones in the human body work in harmony with each other. A medical condition in any of these organs and joints affects the overall body negatively. For example, the deformation in the foot structure, which allows anatomically walking, standing upright, carrying body weight, and moving, affects physical fitness and quality of life [54].

There are many foot deformities in society, but pes planus and pes cavus negatively influence the community's productivity most. Therefore, diagnosis and treatment of the pes planus and pes cavus is of upmost importance to the society.

In the light of the above, this study aims to implement a mobile pre-diagnosis system for pes planus and pes cavus that uses image processing and deep neural networks to utulize traditional deformity recognition methods on a mobile phone app.

Accordingly, this paper is structured as follows; Section 2 introduces the overview of pes planus and pes cavus and previous research in the area. Section 3 provides an overview of the methodologies used in this domain. Section 4 contains the analysis and design of the proposed system. The following section presents the implementation of the prototype. Then the test and evaluation process of the paper is discussed in section 6. In section 7 discusses the results of the developed prototype system. The last section concludes and highlights the finding of this study.

\section{Background}

Accordingly, this section provides overview of important and relevant studies in available medical solutions and detection algorithms in pes planus and pes cavus.

\subsection{Pes Planus \& Pes Cavus}

Irregularities and abnormalities in the normal structure of the medial longitudinal arch produce unbalanced and functionalitywise unstable conditions of the foot such as pes planus or pes cavus. Accordingly, pes planus is the loss of the medial longitudinal arch of the foot, which results with the entire bottom of the foot coming closer to the ground or directly touching the ground during standing or walking [1]. This arch serves as a flexible and adaptive foundation to the entire body [2]. Its functionality is vital to the body since, during the gait cycle, it reduces the pressures of weight-bearing and stores mechanical energy inside the stretched elastic ligaments [3]. Even though it may be asymptomatic, a defective medial longitudinal arch can alter the biomechanics of the lower limbs and lumbar spine, causing an increased risk of pain and injury [4].

The etiology of pes planus has multiple factors which can be either acquired or congenital. Most congenital pes planus deformities disappear by the age of six, which is fixed as part of normal human body development [5]. However, some congenital instances may continue after adulthood, these are mainly related to obesity [6]. Nevertheless, pes planus can be acquired as a result of other dysfunctioning extremities. One of the most common ways of acquiring pes planus is through functional problems related to the posterior tibial tendon, which supports the foot's arch and inversion and plantarflexion. Females over 40 with comorbidities such as diabetes and obesity are more likely to have posterior tibial tendon impairment [7]. In addition, pes planus can be developed more commonly in patients with congenital ligamentous laxity secondary to Down syndrome, Marfan, or Ehlers Danos. Also, patients with midfoot or hindfoot trauma, such as navicular, first metatarsal and calcaneal fracture or Lisfranc ligament complex injury, can commonly develop pes planus.

On the other hand, pes cavus is a deformity that is characterised by elevation of the plantar longitudinal arch of the foot. The array of related deformities observed with pes cavus includes clawing of the toes, posterior hindfoot deformity, contracture of the plantar fascia, and defects in the great toe. Pes cavus is commonly a symptom of an underlying neurological disorder [8].

\subsection{Available Medical Detection Solutions}

Clinical examination, somatometric measurement, radiological evaluation, and ultrasonographic reviews have been used to detect pes planus and pes cavus. However, inked or digital footprints (pressure measurements) and photographic techniques are also used to detect pes planus and pes cavus in the literature, which are called indirect - i.e. non-anthropometric, measurements $[9,10]$. The most accepted and widely used pes planus and pes cavus detection method are the Radiological evaluations [11,12].

Considering the well accepted radiographic detection approach, Chung et al. [13] bases their work to compare the arch index and radiological results of 103 subject's navicular and talar heights. Accordingly, their evaluations show that Clarke's angle, Chippaux-Smirak index, Staheli arch index respectively have $83.89 \%, 90.54 \%$ and $85.43 \%$ probability of prediction in preschool-aged children. Another study by Pauk et al. [14] compares Clarke angle and radiography measurements of sixty children. They also found a correlation between radiography and footprint method. Similarly, many studies have looked into the correlation between radiography and footprint methodologies [15, $16,17]$.

Besides the above comparisons, there are a variety of studies in the literature that only use indirect methods to detect pes planus or pes cavus, such as arch index [18, 19] or planimeter [20]. Therefore, the usability of the indirect methods are proven to be successful.

Igbigbi et al. [19] used an arch index (footprint ratio) to determine arc type and pes planus ratio on 305 Maldivians subjects with their ages ranging between 13 and 17. In this study, participant foot data is collected by creating an imprint of the subject's sole using ink and a piece of paper. The authors note that the method used is more precise, robust, and cost-effective.

On the other hand, Kanatli et al. [15] compared radiologic measurements and footprint methods to determine the correlation between the two methods with 38 pre-schoolers and school-aged children with average age of 6.4 (ages ranging between 3.7-11.7). Based on the findings, the authors highlight significant correlation between arch index, talo-first metatarsal angle, and talohorizontal angle. On the other hand, they found no significant correlation between arch index, calcaneal pitch, and lateral talocalcaneal angles.

With a similar Notion, a study [21] comparing footprint and radiographic measurements, which was conducted on 338 people, discovered a strong correlation between Staheli index, ChippauxSmirak index and Grivas Classification System. On the other hand, as a result of the finding the authors emphasise that there is a weak correlation between the radiological measurement 
methods calcaneal pitch angles and talo-first metatarsal angle and all three footprint measurement methods. Furthermore, the study results indicate that there is no significant correlation between talo-horizontal angle and footprint measurement methods.

\subsection{Pes Planus \& Pes Cavus Detection Algorithms}

There are many developed systems to detect foot deformities, ranging between straightforward solutions such as planimeter [20] and much more complex systems like gait analysis [22].

Most commercially available systems use gait analysis [23, $24]$ to detect a variety of foot deformities. In addition, some of these systems use optical motion capture systems (OMCS) [25] to detect foot deformities. However, having this additional hardware for further precision increases the required investment amount.

On the other hand, some companies are developing low-cost products to fill the gap in the market by sacrificing sensitivity, such as Sennotech's Senno Gait. Sennotech [23] uses economical sensor and AI models for gait analysis. These systems are less expensive and accessible, providing various information such as injury risks and incorrect movement.

Pressure detection devices [26, 27] are also used in many studies $[28,29,30]$. The proliferation of these devices are much wider than the OMCS tools but they provide less feedback. As an example to these kind of studies, In their work, Buldt et al. [28] used EMED, a pressure detection system to determine pes planus and pes cavus.

\section{Methodolog}

Accordingly, this section provides an overview of the methodologies used in pes cavus and pes planus detection, machine learning, and image processing.

\subsection{Pes Planus Pes \& Cavus Detection}

Radiological images are one of the most effective ways of detecting pes planus and pes cavus. However, pes planus and pes cavus may only be visible while feet are pressuring on the sole. Therefore, radiological images are taken while pressing the foot on the ground and as a result, lateral radiographs are taken sideways or from the top of the knee and downwards for arch measurements.

There are many methods that have been used in the literature to determine the status of the foot using radiological images. The most popular of all can be named as calcaneal inclination angle, first metatarsal declination angle and Meary's angle.

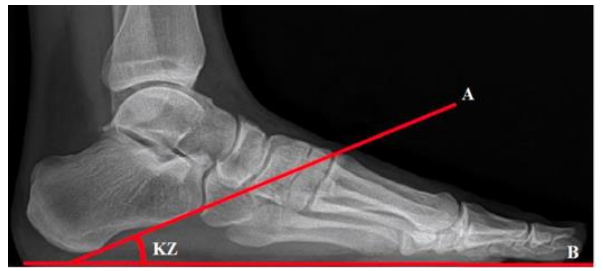

Figure 1. Calcaneal inclination angle [31]

Calcaneal inclination angle (Figure 1) is the angle between the tangent line drawn from the lower face of the calcaneus and the ground [31]. The foot in question is considered healthy if the calcaneal inclination angle is between 20 and 25 degrees. However, if the angle is less than 15 degrees then it is considered to be pes planus [32]. On the other hand, if the angle is larger than 30 degrees then it is regarded as pes cavus [33].
Metatarsal declination angle [31] is calculated using weightbearing lateral foot radiograph and considering the calcaneal inclination axis and the horizontal surface underneath the foot's sole. In the general population the metatarsal declination angle is expected to be about 21 degrees [33]. Any cases where the metatarsal declination angle is larger than 30 degrees is considered to be pes planus [33].

Meary's angle [31] is measured by drawing a line from the centers of longitudinal axes of the talus and the first metatarsal. If the resulting angle is greater than 4 degrees (convex downward) then the foot is considered to be pes planus [34]. On the other hand, if the calculated angle is less than -4 degrees (convex upward) then the foot is considered to be pes cavus [35].

Considering the anthropometric pes planus and cavus detection techniques mentioned above, the non-anthropometric measurements, even though less accurate, are much more easily accessible, less costly to conduct and less hazardous - i.e. require people to expose themselves to radiation. As a result of its ease of access, the non-anthropometric techniques can be conducted en masse and perform examinations in advance.

One of the most popular non-anthropometric methods used in the literature is the footprint approach, which involves sinking the foot into ink and then pressing it onto a graph paper. There are many different indexes that utilize the graph paper to determine pes planus and pes cavus - such as Staheli arch Index and Chippaux-Smirak index.

The Staheli index is calculated by dividing the width of a foot's central region to the width of the heel region. If the identified ratio (index) is larger than 0.8 then the foot is considered to be pes planus. On the other hand, if the calculated ratio is less than 0.4 , then it is considered pes cavus [36].

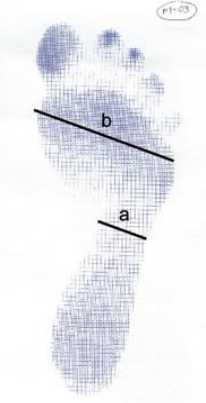

\section{Figure 2. Chippaux-Smirak Index (a/b) [56]}

Chippaux-Smirak Index (Figure 2) is calculated by considering the proportion between the narrowest and widest region of the midfoot. In the Chippaux-Smirak Index, if the proportion is more than 0.45 , it is considered pes planus. If the proportion is less than 0.25 , then it is considered pes cavus[36].

\subsection{Machine Learning}

Machine Learning (ML) is the ability of machines to learn from experiences, make decisions regarding similar situations in the future, and produce solutions to problems [37].

One of the subsets of ML is Supervised Learning (SL). SL requires external intervention or an internal mechanism to achieve the desired output. In SL, the algorithm is expected to correct results in a test set that demands the generalization of learning algorithms. Subsequently, algorithms outputs are expected to be accurate in new datasets. 
Deep learning is one of the popular algorithms used for object detection, which is a subclass of machine learning and can be either supervised (such as classification) or unsupervised. Accordingly, deep learning uses many non-linear processing unit layers for feature extraction and conversion. Therefore, each successive layer takes the output from the previous layer as input and finally results with a classification. For example, a popular framework used in image processing is CNN (convolutional neural network), which consists of one or more convolutional layers, a subsampling layer and followed by one or more fully connected layers such as a standard multilayer neural network [38].

Besides classification, also establishing the location of the object in an image is another challenge in the domain of image processing. One of the first region-based architectures is R-CNN (Region-based convolutional neural network), which uses selective search to reduce the search region up to 2000 areas. Following suit with the previous algorithm, after the region reduction stage, a typical $\mathrm{CNN}$ is applied to extract features. Finally, the extracted features fed into a vector support machine to produce the results [39]. Following R-CNN, there are many algorithms that have been developed and proposed, which are further increasing the speed and accuracy of the R-CNN such as Fast R-CNN [40], Faster R-CNN [41], YOLO [42].

Another challenging problem in this domain is the Semantic segmentation. Semantic segmentation can be solved by tagging raw pixels in an image with the object category. For example, a Fully Convolutional Network (FCN) takes an image and produces a segmented image of the same size as input. Thus, distinct probability values are obtained for each pixel in the input image [43]. As a result, FCN [39] is very successful in the one-to-one mapping of each pixel without region. Accordingly, DeepLabv3 [44] is one of the state-of-the-art semantic segmentation algorithms. The DeepLabv3 architecture is built on top of the ResNet-101 [45] architecture by adding Atous Spatial Pyramid Pooling (ASPP). This module obtains feature maps with different details according to the void ratios of the filters by applying convolution filters with different void ratios on the ResNet output. These maps are then combined and passed through a filter [44]. Our work also makes use of the DeepLabv3 architecture to detect humans in images, which is discussed in section 4 .

\subsection{Image Processing}

Digital image processing is one of the major areas in computer science. The latest research shows that DL has significant breakthroughs in the area with large data sets and increased resources in computational power [46, 47].

On the other hand, some areas lack large datasets to train DL algorithms. For these areas with dataset scarcity, conventional algorithms such as Sobel [48] can be beneficial for edge detection. Accordingly, Prewitt [49], Sobel [48], and Canny [50] are the most accepted and widely used edge detection algorithms in the literature. Sobel [48] algorithm calculates gradient on each point with respect to surrounding pixels, which is also called the kernel, on the image. In addition, in this algorithm, direction is also considered when calculating gradients.

On the other hand, Canny [50] is a more compact algorithm which uses a number of steps to detect edges. Firstly, Canny uses a Gaussian filter to eliminate noise in the image. Secondly, changes in the color are detected using gradients. Furthermore, this second step also maintains a threshold value to remove any existing noise. Lastly, edges that are not strongly connected to any other edges are removed to filter out the most obvious ones.

Literature shows that Sobel is still improved [51] and used in many research projects $[52,53]$. Since our project requires something bit more advance version of the Canny, Sobel algorithm is chosen and used different kernels and directions to detect the foot sole.

\section{Analysis \& Design}

Accordingly, this section provides an overview of the analysis and design, which includes requirements capturing and modelling and furthermore, explains overall structure of the protytpe.

\subsection{Requirements Capturing}

The system will provide the preliminary detection of potential pes planus and pes cavus patients. Therefore, the system should contain three essential structures: End-User Interface, Healthcare Interface, and last but not least, Backend services which will relay the data in between the two structures.

The end-user application should cater $\% 95$ of the mobile device users. In addition, the system should be able to detect pes planus and pes cavus with at least $\% 70$ accuracy, which as a result would reduce the workload of healthcare officials. Moreover, the end user application should produce the pre-diagnosis results provided by the system to the user within two minutes.

Furthermore, the prototype system should give an overall idea to the healthcare personnel and provide them with a provisional result. Hence, the final validation and confirmation of the result should be conducted by the healthcare personnel. However, in order to achieve this, there is a need for a web portal interface where the medical personnel could log in and keep track of their patients.

\subsection{Modelling}

Considering the above requirements, the system should be divided into two essential modules that feed each other to enable maximum efficiency - namely data and fine-tune modules. These modules should be designed in such a way that they would enable continuous improvement as can be seen in Figure 3 .

Accordingly, the data module should focus on information collection and initial pre-diagnosis. Furthermore, this module should collect and process the essential and detailed information regarding the users, which consists of three parts: essential, health, and foot information.

The essential information should collect the name, surname, email address, birthdate. Also, in order to continue receiving the service, the users should be required to read and accept a consent form, which would explain to users how the collected data will be stored and processed.

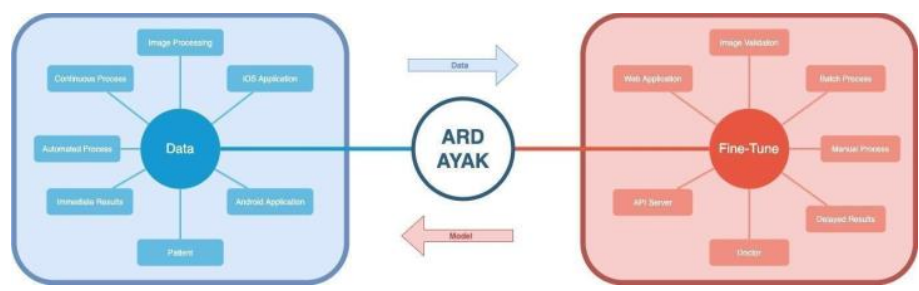

Figure 3. Data \& Fine-Tuning Module 
The health information collection part should focus on collecting the user's existing health issues related to pes planus and pes cavus. It should also collect any health issues that require the immediate attention of health workers. Therefore, if such a case arises it should directly ask the user to make an appointment with the physician for an emergency consultation. In addition, the prototype system should have a rule-based approach to detect health issues such as night pain level etc.

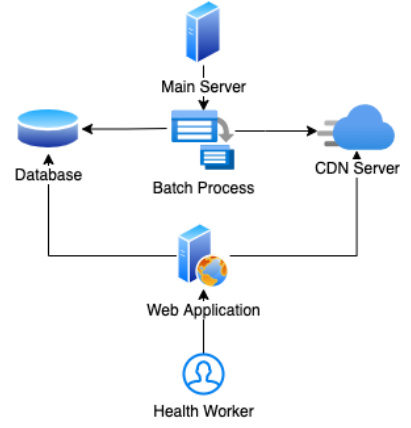

Figure 4. Detailed view of Fine-Tuning Module

Lastly, informatim about the feet should be collected. These would includes information such as the degree of pain in physical activities, degree of pain at night, and most importantly pictures of the foot taken by the user him or herself. In addition, optionally users should be able to enter information about the deformity of the foot, if previously diagnosed.

The fine-tuning (Figure 4) module will be involved with background processes and healthcare professionals' interactions. Therefore, this module should contain two critical functions, namely system improvements and user interactions. In this module, initially healthcare professionals, who are also called system managers, would interact and review the user-provided data and conduct refinements on the system diagnoses. Later, the system would use the data doctored and tweaked by the system managers to actively improve the pre-diagnosis.

However, in order to achive this, a web application would be needed for system managers to display and review the user provided content, such as foot images, previous diseases information and medical background. In the web application the system managers should also be able to calculate the different foot indexes - i.e. Staheli Arch Index - on images provided by the users. To calculate these indexes, system managers would only require to mark the critical points on a foot image. Consequently, the index calculation would be generated and the medical professional guided in their decision making and diagnoses.

The batch process would be the part of the fine-tuning module whose primary purpose is to improve the pre-diagnosis and analyze the healthcare professionals' diagnoses and critical points. Initially, this process will be designed to work manually, but it could be changed into an automated process for continuous learning after collecting enough data. Lastly, the batch is also responsible for the reporting results such as average successful pre-diagnoses. There would be multiple error calculations as part of the batch process in order to create the required analysis and and results.based on patient data. As a result, in these cycles, detailed errors would provide a benchmark to the batch process and recursively help improve its findings

From a different perspective, bearing in mind that all collected data is confidential, storaging, accessing and transmiting of the data should be handled with extreme vigilance and care. Accordingly, all data transmissions on the network will e-ISSN: 2148-2683 be encrypted. Furthermore, all users accessing this data will be required to authenticate. Also, at the end of the study, all information collected from the users will be deleted.

\section{Implementation}

Some parts of this protorype contain well-defined requirements and design models, however, on the other hand, some other parts such as mobile client has more dynamic structure where its requirements are changed based on the feedback received from the pilots users.

The client application follows the prototyping development model since our primary focus is collecting users' materials (foot pictures, deformity types, etc.). For example, initially, the iOS operating system was planned to be supported, but considering how diverse the mobile market is also an Android prototype was also introduced. On the other hand, server APIs were less prone to changes. Therefore, a waterfall model is adopted fort the implemetion of the server-side application. Furthermore, the core pre-diagnoses part of the application, where pes planus and pes cavus detection were undertaken embraced more of a Agile development model.

Accordingly, the iOS client app (Figure 5) is compatible with iOS 11 and newer versions, making it available for $99,7 \%$ of the iOS device market. Since Swift language is selected for the development of the client, it results with an application that is easily extendable from features point of view and more intergratable from compatibility and iOS ecosystem point of view.

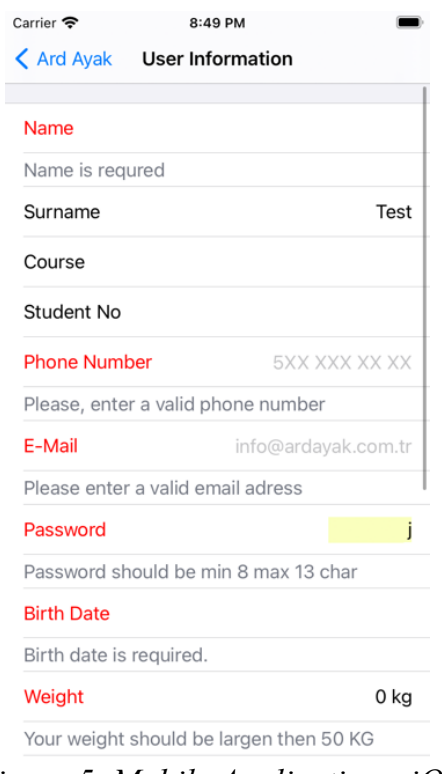

Figure 5. Mobile Application - iOS

On the other hand, the Android flavour of the client is compatible with Android devices API level 16 and newer version, which makes it available for $99,8 \%$ of the Android device market. In the development of the Android client the Flutter software development kit is used, which requires Dart programming language. As a result, makes the final software product compatible with iOS and Android operating systems. On the other hand, this dual-platform development using Flutter requires additional effort, hence, the Flutter application is only used in the implementation of the Android clients. However, in the future this could be changed so that a single development cycle could produce both iOS and Android clients. 
Both end-user applications making use of the underlying operating systems UI follow the same workflow. Therefore, as a result, this enables users to complete their operations more comfortably and consistently with the UI they frequently use and they are familiar with. Furthermore, a user documentation is created to help improve the user experience and enhance how the users interact with the ArdAyak application.

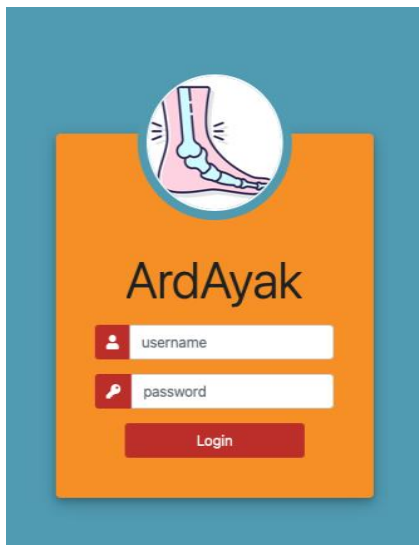

Figure 6. Web Application - Login Page

Localization of an app is one of the important traits in the globalized world. The prototype client app supports multiple languages to increase international userbase in multiple regions. Therefore, ArdAyak client apps, for both operating systems, are designed so that the task of adding a new language would be as simple and straightforward as adding a new language definition file to the app's language filebase. Additionally, to further support multilingual nature of its desig, the application makes use of the operating system-level localization tools to offer users features such as running the app by default in user's pereferencial language. In the initial release, end-user applications support both English and Turkish to serve a variety of users.

On the other hand, the web application is designed to work on all modern browsers such as Chrome and Safari. It has a simplistic graphical user interface which enables users to have an intuitive interaction with the system (Figure 6). Moreover, the web application also has validation and critical point assistance (Figure 7) to reduce user originating errors - such as virtual lines between the pins.

The overall system is designed to provide two different types of service; mobile application and web application, which will each cater respectively to end-users and healthcare personnel. The underlying purpose of implementing the system with two facets is to increase its scalability. Accordingly, there would be one subsystem dealing with multiple end-user interactions and data sent via the mobile up. On the other hand, another sub-system, which may reside on a totally different physical server, would be carrying out batch processes and serving the medical personnel. Following this analogy, the store could be run on an independent sub-system safe and secure from direct access from the Internet. By following this layered approach, the end-users would carry out their transaction faster, on the other hand, medical personnel would have access to a much more powerful and interactive system. Last but not least, the data storage would be safer since it is not directly accessible by neither the medical personnel nor the end-user systems.

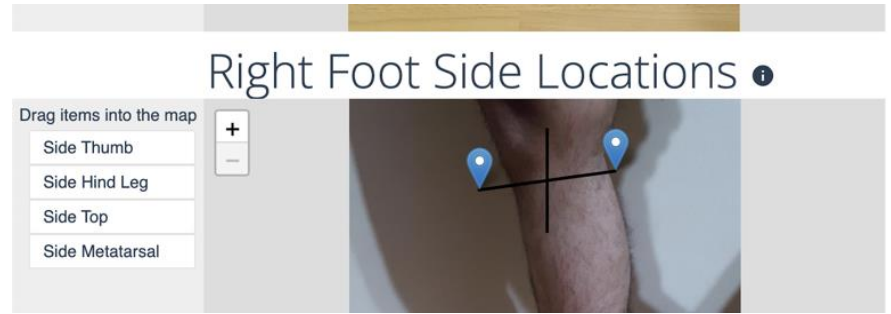

Figure 7. Critical Point Assistance

The end-user service uses microservice architecture to help rapid development. This enables us to deliver features more quickly to the production environment. Moreover, JWT(JSON Web Tokens - RFC7519) is used for authentication to prevent unauthorized access. Lastly, it has to be highlighted that all communication via HTTP protocol is encrypted with Secure Sockets Layer (SSL - RCF6101).

In the epicenter of this system is the batch process, which is where the main computational algorithms are executed. Accordingly, this facet conducts image processing, which entails the following steps: (1) region of interest; (2) image preparation and (3) image processing. After these steps are executed their findings are recorded on the relevant database.

In the first step, deep learning algorithms are applied to find the (1) regions of interest in the images. Considering that the existing datasets mostly contain full human body images and in this solution the objective is to detect body parts rather than full human body, multiple algorithms (such as YOLO, MIDAS, FCN_Resnet101, DeepLabV3) were tested to get the best result when they are applied to partial human body parts in an image such as foot and parts of the leg. From all of the algorithms listed above the best performance was achieved by DeepLabV3.

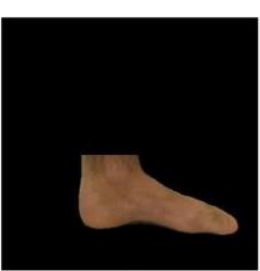

A

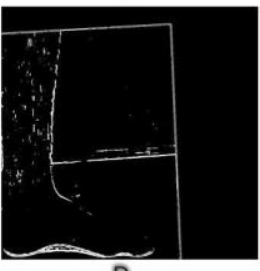

D

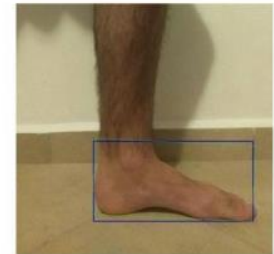

B

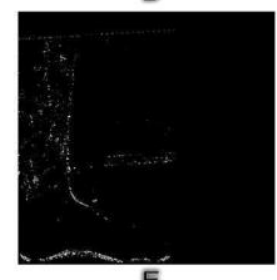

E

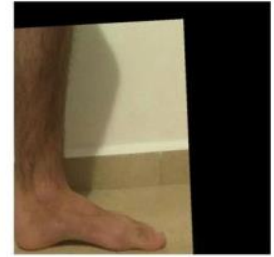

C

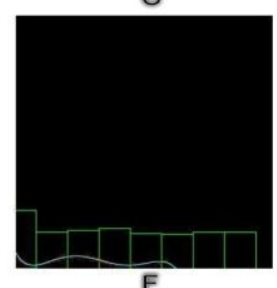

F
Figure 8. Image Processing

After the body parts in the images are detected using the algorithm mentioned above (see Figure 8A), a minimum area rectangle (Figure $8 \mathrm{~B}$ ) is calculated and used to surround the body part in the overall picture. Then, this area is further processed and a perspective transformation (Figure 8C) is applied to localize the critical points.

In order to detect the contour of the foot's sole, Sobel edge detection algorithm needs to be applied to the image. However, the Sobel algorithm requires grayscale images and therefore, colored images first need to be converted to HSL color space. At this stage HSL color space is selected because the HSL is less sensitive to light since its light channel is different. In our context, this is very important because end-users most of the time take 
pictures in various lights and shades. For the very same reason, the $\mathrm{S}$ channel was selected for the conversion, which is the best performer in overall color space. By performing all of the above tasks (2) the image preparation step is finalized.

At this stage, as the image is converted into HSL, the S channel values are fed into the Sobel edge detection algorithm. During the edge detection process, multiple Sobel conversions are applied and merged into one edge image. For example, the order of the derivative in ' $x$ ' and ' $y$ ' direction is applied in kernel size of 9 to images in Sobel conversions. In addition, threshold values are also used to remove unnecessary edges in images which can be seen in Figure 8E.

Lastly, foot line detection is applied. Predefined window size all non-zero points extracted. After point extraction, the fifthorder (Quintic) polynomial is fitted to points which can be seen in Figure 8F.

After the foot sole is extracted, the Arc index is calculated. This calculation is based on the ratio of critical points in the foot, which does not require reversal of the perspective transformation. Consequently, the points location (top, bottom, and metatarsal) calculated using foot solo equation.

\section{Results and Evaluation}

This section describes the tests and evaluations conducted on the prototype system that has been described in the previous parts of the paper.

Considering the core functionality of the prototype system, the most important aspect is to evaluate whether the system can successfully classify foot deformities or non-deformities. As part of the evaluation, the collected foot pictures were shared with the physician and he was asked to calculate the Arch Index for each one of them. Then received calculations were compared with the automated algorithm's findings.

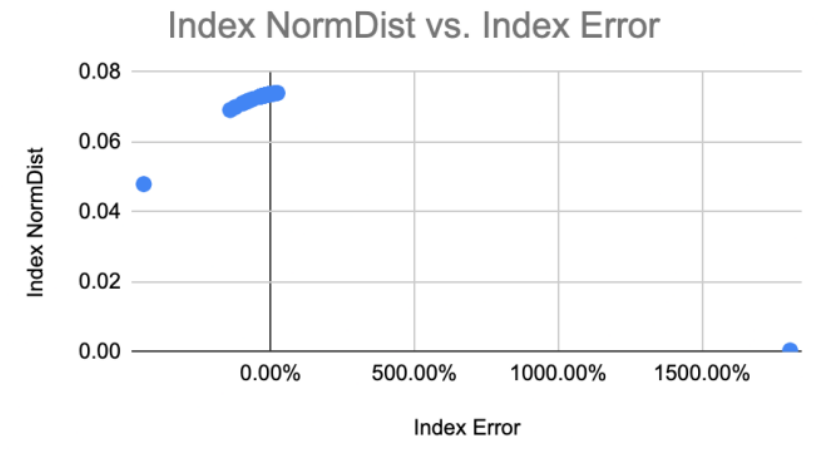

Figure 9. Index Errors Normal Distribution

Accordingly, the prototype was distributed to 34 participants - $22(64,71 \%)$ males and $12(35.29 \%)$ females - with an average age of 24,06 and they were asked to take pictures of their feet using the prototype app. All data uploaded by the participants then was stored on an online database.

Since none of the data collection was conducted under supervision, some image data uploaded to the server were unusable and not fit for processing. Therefore, some of the images were removed from the database. As a result, 61 foot pictures, out of 68 foot images ( 2 feet per participant), were cleared for processing.
Initially, as mentioned above, the 61 foot pictures were shared with the physician and their Arch Index values were manually calculated. The findings of the physician showed that $93 \%$ of the foot pictures were classified as pes planus and the remaining 7\% foot pictures were classified as normal feet.

After obtaining the manually calculated Arch Index values from the physician, the same foot images were fed to the prototype batch process. The foot type classification findings of the automated algorithm and the physician's were $91.80 \%$ match. Since the participant pool was generated using the general public, with no specific foot disorders, the results were not that diverse.

Considering the high percentage of $(93 \%)$ of images being classified as pes planus, it was questioned whether there was a bias in the prototype algorithm towards pes planus. Therefore, a further analysis is conducted on the images where physicians selected index points and automatically identified index points were compared and their deviations calculated. Accordingly, the deviation comparison showed that in some cases where the image corrupted the error rates are substantially high but this most of the time is related to human error. The comparison showed that the standard deviation index error is 5.377. In some cases arch index error is as low as $0.02 \%$ which is a proof that the newly designed algorithm performed as required.

\section{Conclusion}

This study aims to implement a mobile pre-diagnostic tool that would help physicians in classifying and identifying potential patients with foot deformities - namely pes cavus, pes planus remotely. Accordingly, this solution makes use of the client/server model to create the prototype, where the client side is used to collect the raw data and foot pictures and the server side to process and store the collected data. On the server side, the collected data is processed using machine learning, image processing, and deep neural networks.

The implemented prototype then is tested with 34 participants and the overall evaluation showed that the pre-diagnoses prototype, acknowledging its shortcomings with non-clear images, has great potential and can identify pes cavus and pes planus $91.80 \%$ success when compared to a physician's findings.

However, the prototype, as acknowledged above, still has its shortcomings and space for improvement in pre-processing and clarification of pictures with non-ideal background or lighting.

\section{References}

Michaudet, C., Edenfield, K. M., Nicolette, G. W., \& Carek, P. J. (2018). Foot and Ankle Conditions: Pes Planus. FP essentials, $465,18-23$.

Franco, A. H. (1987). Pes cavus and pes planus: analyses and treatment. Physical therapy, 67(5), 688-694.

Kelly, L. A., Cresswell, A. G., \& Farris, D. J. (2018). The energetic behaviour of the human foot across a range of running speeds. Scientific reports, 8(1), 1-6.

Aenumulapalli, A., Kulkarni, M. M., \& Gandotra, A. R. (2017). Prevalence of flexible flat foot in adults: a cross-sectional study. Journal of clinical and diagnostic research: JCDR, 11(6), AC17.

Mickle, K. J., Steele, J. R., \& Munro, B. J. (2006). The feet of overweight and obese young children: are they flat or fat? Obesity, 14(11), 1949-1953. 
Woźniacka, R., Bac, A., Matusik, S., Szczygieł, E., \& Ciszek, E. (2013). Body weight and the medial longitudinal foot arch: high-arched foot, a hidden problem?. European journal of pediatrics, 172(5), 683-691.

Kohls-Gatzoulis, J., Woods, B., Angel, J. C., \& Singh, D. (2009). The prevalence of symptomatic posterior tibialis tendon dysfunction in women over the age of 40 in England. Foot and Ankle Surgery, 15(2), 75-81.

DA, B., \& DR, S. (1963). " IDIOPATHIC" PES CAVUS: AN INVESTIGATION INTO ITS AETIOLOGY. British Medical Journal, 2(5358), 659-661.

Gün, K., SaridoĞan, M., \& Uysal, Ö. (2012). Pes Planus Tanısında Ayak İzi ve Radyografik Ölçüm Yöntemlerinin Korelasyonu. Turkish Journal of Physical Medicine \& Rehabilitation/Turkiye Fiziksel Tip ve Rehabilitasyon Dergisi, 58(4).

Yalçın, N., Esen, E., Kanatlı, U., \& Yetkin, H. (2010). Medial longitudinal arkın değerlendirilmesi: dinamik plantar basınç ölçüm sistemi ile radyografik yöntemlerin karşılaştırılması. Acta Orthop Traumatol Turc, 44(3), 241-5.

Smith, D. G., Barnes, B. C., Sands, A. K., Boyko, E. J., \& Ahroni, J. H. (1997). Prevalence of radiographic foot abnormalities in patients with diabetes. Foot \& ankle international, 18(6), 342346.

Winfeld, M. J., \& Winfeld, B. E. (2019). Management of pediatric foot deformities: an imaging review. Pediatric radiology, 49(12), 1678-1690.

Chen, K. C., Yeh, C. J., Kuo, J. F., Hsieh, C. L., Yang, S. F., \& Wang, C. H. (2011). Footprint analysis of flatfoot in preschool-aged children. European journal of pediatrics, 170(5), 611-617.

Pauk, J., Ihnatouski, M., \& Najafi, B. (2014). Assessing plantar pressure distribution in children with flatfoot arch: application of the Clarke angle. Journal of the American Podiatric Medical Association, 104(6), 622-632.

Kanatli, U., Yetkin, H., \& Cila, E. (2001). Footprint and radiographic analysis of the feet. Journal of Pediatric Orthopaedics, 21(2), 225-228.

Yalçin, N., Esen, E., Kanatli, U., \& Yetkin, H. (2010). Evaluation of the medial longitudinal arch: a comparison between the dynamic plantar pressure measurement system and radiographic analysis. Acta Orthop Traumatol Turc, 44(3), 241-5.

Menz, H. B., \& Munteanu, S. E. (2005). Validity of 3 clinical techniques for the measurement of static foot posture in older people. Journal of Orthopaedic \& Sports Physical Therapy, 35(8), 479-486.

Cavanagh, P. R., \& Rodgers, M. M. (1987). The arch index: a useful measure from footprints. Journal of biomechanics, 20(5), 547-551.

Igbigbi, P. S., \& Msamati, B. C. (2002). The footprint ratio as a predictor of pes planus: a study of indigenous Malawians. The Journal of foot and ankle surgery, 41(6), 394-397.

Didia, B. C., Omu, E. T., \& Obuoforibo, A. A. (1987). The use of footprint contact index II for classification of flat feet in a Nigerian population. Foot \& ankle, 7(5), 285-289.

Gun, K., Saridogan, M., \& Uysal, O. (2012). The correlation between footprint and radiographic measurements in flatfoot.

Buldt, A. K., Levinger, P., Murley, G. S., Menz, H. B., Nester, C. J., \& Landorf, K. B. (2015). Foot posture is associated with kinematics of the foot during gait: A comparison of normal, planus and cavus feet. Gait \& posture, 42(1), 42-48.
Sennotech Co. Ltd. Gait Analysis Product. Retrieved August 16, 2021, from https://www.sennotech.com/en/index.php

alFOOTs Co. Ltd. 4ch PGO Gait Analysis Product. Retrieved August 20, 2021, from https://alfoots.com:5000/en/sub/02_sub/02_sub02.php

Vicon Motion Systems Ltd. Optical Motion Capture Cameras. Retrieved August 24, 2021, from https://www.vicon.com/hardware/cameras/

novel GmbH, emed Pressure Detection Device. Retrieved August 15, 2021, from https://www.novel.de/products/emed/

medilogic $\mathrm{GmbH}$, emed Pressure Detection Device. Retrieved August 17, 2021, from https://medilogic.com/en/pressuremeasuring-platform-nx/

Buldt, A. K., Forghany, S., Landorf, K. B., Levinger, P., Murley, G. S., \& Menz, H. B. (2018). Foot posture is associated with plantar pressure during gait: A comparison of normal, planus and cavus feet. Gait \& posture, 62, 235-240.

Keukenkamp, R., Busch-Westbroek, T. E., Barn, R., Woodburn, J., \& Bus, S. A. (2021). Foot ulcer recurrence, plantar pressure and footwear adherence in people with diabetes and Charcot midfoot deformity: A cohort analysis. Diabetic Medicine, 38(4), e14438.

Bosch, K., Gerß, J., \& Rosenbaum, D. (2010). Development of healthy children's feet - nine-year results of a longitudinal investigation of plantar loading patterns. Gait \& posture, 32(4), 564-571.

DENIZ, G., KAVAKLI, A., ÖGETÜRK, M., ÖZTÜRK, D., TATAR, N., \& PERİLIOĞLU, A. Z. (2014). Çocuklardaki Fleksibl Pes Planusun Yüklü ve Yüksüz Radyografilerle Değerlendirilmesi. Fırat Üniversitesi Sağlık Bilimleri Tıp Dergisi, 28(3), 129-132.

Flores, D. V., Mejía Gómez, C., Fernández Hernando, M., Davis, M. A., \& Pathria, M. N. (2019). Adult acquired flatfoot deformity: anatomy, biomechanics, staging, and imaging findings. Radiographics, 39(5), 1437-1460.

Yates, B., \& Merriman, L. M. (Eds.). (2009). Merriman's assessment of the lower limb. Elsevier Health Sciences.

Vanderwilde, R. U. S. S. E. L. L., Staheli, L. T., Chew, D. E., \& Malagon, V. A. L. E. N. T. I. N. (1988). Measurements on radiographs of the foot in normal infants and children. The Journal of bone and joint surgery. American volume, 70(3), 407-415.

Banks, A. S. (2001). McGlamry's comprehensive textbook of foot and ankle surgery (Vol. 1). Lippincott Williams \& Wilkins.

Almaawi, A., Alotaibi, N., Alsubaie, M., Altwaijri, N., Alduraibi, K., Awwad, W., \& Algarni, A. (2019). Flatfoot Prevalence in Riyadh City Saudi Arabia And Its Association with Obesity, Using Three Footprint Indices; Clarkâ€TM s Angle, ChippauxSmirak Index, and Staheli Index. Orthopedics and Rheumatology Open Access Journals, 15(2), 52-58.

Michie, D., Spiegelhalter, D. J., \& Taylor, C. C. (1994). Machine learning, neural and statistical classification.

Ciregan, D., Meier, U., \& Schmidhuber, J. (2012, June). Multicolumn deep neural networks for image classification. In 2012 IEEE conference on computer vision and pattern recognition (pp. 3642-3649). IEEE.

Girshick, R., Donahue, J., Darrell, T., \& Malik, J. (2014). Rich feature hierarchies for accurate object detection and semantic segmentation. In Proceedings of the IEEE conference on computer vision and pattern recognition (pp. 580-587).

Girshick, R. (2015). Fast r-cnn. In Proceedings of the IEEE international conference on computer vision (pp. 1440-1448). 
Ren, S., He, K., Girshick, R., \& Sun, J. (2015). Faster r-cnn: Towards real-time object detection with region proposal networks. Advances in neural information processing systems, 28, 91-99.

Redmon, J., \& Farhadi, A. (2018). Yolov3: An incremental improvement. arXiv preprint arXiv:1804.02767.

Long, J., Shelhamer, E., \& Darrell, T. (2015). Fully convolutional networks for semantic segmentation. In Proceedings of the IEEE conference on computer vision and pattern recognition (pp. 3431-3440).

Chen, L. C., Papandreou, G., Schroff, F., \& Adam, H. (2017). Rethinking atrous convolution for semantic image segmentation. arXiv preprint arXiv:1706.05587.

He, K., Zhang, X., Ren, S., \& Sun, J. (2016). Deep residual learning for image recognition. In Proceedings of the IEEE conference on computer vision and pattern recognition (pp. 770-778).

Razzak, M. I., Naz, S., \& Zaib, A. (2018). Deep learning for medical image processing: Overview, challenges and the future. Classification in BioApps, 323-350.

Hemanth, D. J., \& Estrela, V. V. (Eds.). (2017). Deep learning for image processing applications (Vol. 31). IOS Press.

Gonzalez, R. C., \& Woods, R. E. (1992). Digital Image Processing Addison-Wesley. Reading, Ma.

Prewitt, J. M. (1970). Object enhancement and extraction. Picture processing and Psychopictorics, 10(1), 15-19.

Canny, J. (1986). A computational approach to edge detection. IEEE Transactions on pattern analysis and machine intelligence, (6), 679-698.

Vinista, P., \& Joe, M. M. (2019). A Novel Modified Sobel Algorithm for Better Edge Detection of Various Images. International journal of emerging technologies in engineering research (IJETER), 7(3), 26-31.

Yusoff, N. M., Halim, I. S. A., \& Abdullah, N. E. (2018, August). Real-time hevea leaves diseases identification using Sobel edge algorithm on FPGA: A preliminary study. In 2018 9th IEEE Control and System Graduate Research Colloquium (ICSGRC) (pp. 168-171). IEEE.

Rezai-Rad, G., \& Aghababaie, M. (2006, April). Comparison of SUSAN and sobel edge detection in MRI images for feature extraction. In 2006 2nd International Conference on Information \& Communication Technologies (Vol. 1, pp. 1103-1107). IEEE.

Lee, M. S., Vanore, J. V., Thomas, J. L., Catanzariti, A. R., Kogler, G., Kravitz, S. R., ... \& Gassen, S. C. (2005). Diagnosis and treatment of adult flatfoot. The Journal of Foot and Ankle Surgery, 44(2), 78-113.

Cheung, Z. B., Myerson, M. S., Tracey, J., \& Vulcano, E. (2018). Weightbearing CT scan assessment of foot alignment in patients with hallux rigidus. Foot \& ankle international, 39(1), 67-74.

Vaseenon, T., Wattanarojanaporn, T., Intharasompan, P., Theeraamphon, N., Auephanviriyakul, S., \& Phisitkul, P. (2015). Foot and ankle problems in Thai monks. J Med Assoc Thai, 98(1), 71-6. 